\title{
The impact of aberrant von Willebrand factor-GPIb $\alpha$ interaction on megakaryopoiesis and platelets in humanized type 2B von Willebrand disease model mouse
}

\author{
Sachiko Kanaji,,2 Yosuke Morodomi, ${ }^{1}$ Hartmut Weiler, ${ }^{2}$ Alessandro Zarpellon, ${ }^{1,3}$ Robert R. \\ Montgomery, ${ }^{2,4,5}$ Zaverio M. Ruggeri ${ }^{1,3}$ and Taisuke Kanaji ${ }^{1,2}$

\begin{abstract}
'Department of Molecular Medicine, MERU-Roon Research Center on Vascular Biology, The Scripps Research Institute, La Jolla, CA; ${ }^{2}$ Blood Research Institute, Blood Center of Wisconsin, Versiti, Milwaukee, WI; ${ }^{3}$ MERU-VasImmune, Inc., San Diego, CA; ${ }^{4}$ Children's Research Institute, Children's Hospital of Wisconsin, Milwaukee, WI and ${ }^{5}$ Department of Pediatrics, Medical College of Wisconsin, Milwaukee, WI, USA
\end{abstract}

\author{
Correspondence: S. Kanaji \\ skana@scripps.edu \\ Received: December 22, 2021 \\ Accepted: $\quad$ February 2, 2022. \\ Prepublished: February 10, 2022. \\ https://doi.org/10.3324/haematol.2021.280561 \\ (๑2022 Ferrata Storti Foundation \\ Published under a CC BY-NC license (c) (1) $(2)$
}

\begin{abstract}
Type 2B von Willebrand disease (VWD) is caused by gain-of-function mutations in von Willebrand factor (VWF). Increased VWF affinity for GPIba results in loss of high molecular weight multimers and enhanced platelet clearance, both contributing to the bleeding phenotype. Severity of the symptoms vary among type 2B VWD patients, with some developing thrombocytopenia only under stress conditions. Efforts have been made to study underlying pathophysiology for platelet abnormalities, but animal studies have been limited because of species specificity in the VWF-GPIba interaction. Here, we generated a severe form of type 2B VWD (p.V1316M) knockin mice in the context of human VWF exon 28 (encoding $A 1$ and $A 2$ domains) and crossed them with human GPIba transgenic strain. Heterozygous mutant mice recapitulated the phenotype of type $2 B \mathrm{BWD}$ in autosomal dominant manner and presented severe macrothrombocytopenia. Of note, platelets remaining in the circulation had extracytoplasmic GPIba shed-off from the cell surface. Reciprocal bone marrow transplantation determined mutant VWF produced from endothelial cells as the major cause of the platelet phenotype in type $2 \mathrm{~B}$ VWD mice. Moreover, altered megakaryocyte maturation in the bone marrow and enhanced extramedullary megakaryopoiesis in the spleen were observed. Interestingly, injection of anti-VWF A1 blocking antibody (NMC-4) not only ameliorated platelet count and GPIba expression, but also reversed MK ploidy shift. In conclusion, we present a type $2 \mathrm{~B}$ VWD mouse model with humanized VWF-GPIba interaction which demonstrated direct influence of aberrant VWF-GPIba binding on megakaryocytes.
\end{abstract}

\section{Introduction}

Von Willebrand disease (VWD) is a common inherited bleeding disorder caused by defects in the function or

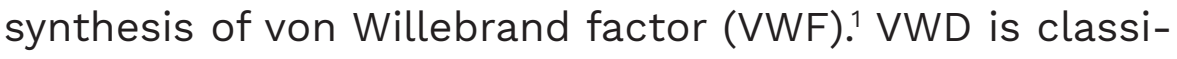
fied into three primary categories: type 1, type 2, and type 3. Among them, type $2 B$ VWD represents variants with increased affinity for platelet GPIba, which is paradoxically associated with bleeding symptoms, not thrombosis. ${ }^{2,3}$ It has been known that enhanced binding of gain-of-function mutant VWF to platelets and accelerated clearance, in combination with higher susceptibility to ADAMTS13, result in loss of the largest VWF multimers and thrombocytopenia. $^{2-4}$ of note, clinical manifestations and results of laboratory tests are heterogeneous among type 2B VWD patients, depending on the mutations involved. ${ }^{5}$ In addition, one unsolved issue in the pathophysiology of type $2 B$ VWD is the regulatory mechanism of aberrant VWF A1GPIba on megakaryocytes (MK) and thrombopoiesis. In addition to accelerated platelet clearance, impaired megakaryopoiesis have also been implicated as the cause of thrombocytopenia. ${ }^{6,7}$

To date, limited research of VWD using mouse models have been reported due to species-incompatibility of VWF A1-GPIb $\alpha$ interaction. Previous efforts have been made to overcome species-specificity in VWF A1-GPIba interaction. ${ }^{8}$ However, later study found that single amino acid substitutions may not be sufficient to fully convert the species-specific binding property, ${ }^{9}$ suggesting that replacement of the entire VWF A1 is desired to mimic human 
VWF A1-GPIb $\alpha$ interaction in vivo. In addition, mouse VWF A1-GPIb $\alpha$ interaction was found not to be identical to that of human. ${ }^{10-12}$ In this study, we report the first mouse model of type 2B VWD having gain-of-function mutation in humanized VWF A1-GPIba interaction. We have employed the strategy to target $V w f$ exon 28 to humanize VWF A1/A2 domains, ${ }^{13}$ and generated type 2B VWD model by mutagenizing the human VWF A1 with the p.V1316M substitution. This strain was bred with humanized GPIb $\alpha$ transgenic strain to humanize VWF A1-GPIbo interaction in vivo. As expected, this model closely recapitulated platelet phenotype of human type 2B VWD in autosomal dominant manner and was proven to be a valuable tool to study the biological effect of VWF A1-GPIb $\alpha$ interaction in vivo.

\section{Methods}

\section{Animal experiments}

All animal procedures were performed in accordance with the National Institute of Health Guideline for the Care and Use of Laboratory Animals. All protocols for animal studies were approved by the Institutional Animal Care and Use Committees (IACUC) of The Scripps Research Institute and Medical College of Wisconsin.

\section{Generation of human von Willebrand factor exon 28 knockin mice with p.V1316M mutation and cross- breeding with human GPIb $\alpha$ transgenic mice}

A new knockin strain having type 2B VWD mutation was generated at the Transgenic Core Facility, Blood Research Institute/Medical College of Wisconsin. The targeting vector previously used to generate a knockin mouse with Vwf exon28 replaced by human homolog (VWF ${ }^{\text {hA1 }}$ ) was used with additional mutagenesis of p.V1316M in the A1 domain..$^{13}$ Correctly targeted embryonic stem cells were injected into blastocyst stage embryos to generate chimeric mice. In order to remove the loxP-flanked Neo cassette, these mice were bred with B6.FVB-Tg (Ella-Cre) C5379Lmgd/J mice (The Jackson Laboratory) and then crossed with the human GPIba transgenic mouse strain in which platelets express only human GPIb $\alpha$ in the GPIbIX-V complex. The knockin strain having human VWF exon 28 with p.V1316M substitution was bred into homozygous (VWF ${ }^{2 B h o m o}$ hGPIb $\alpha$ ). VWF ${ }^{2 B h o m o}$ hGPIb $\alpha$ strain was bred with previously generated VWFA1 hGPIb $\alpha$ strain to generate VWF $^{2 B h e t}$ hGPIb $\alpha$ mice having heterozygous p.V1316M mutation.

\section{Platelet count analysis}

For blood cell counting, blood obtained by retro-orbital bleeding were analyzed using the IDEXX ProCyte ${ }^{\mathrm{TM}}$ (IDEXX Laboratories Inc., Westbrook, ME).

\section{NMC-4 injection study}

Monovalent Fab fragment ${ }^{14}$ expressed in $D$. melanogaster S2 cells was purified from culture supernatant and administered ( $2 \mathrm{mg} / \mathrm{kg}$ ) by retro-orbital vein injection for 4 consecutive days.

\section{Bone marrow hematopoietic stem cell transplantation}

Bone marrow (BM) cells were collected from femurs and tibia of donor mice, and BM mononuclear cells (BM MNC) were isolated using ficoll as described previously. ${ }^{15,16}$ Sixto 8-week-old recipient mice were conditioned with a lethal dose of 1,100 cGy total body irradiation using a Gammacell 40 Exactor cesium irradiator. Twenty-four hours after irradiation, a dose of $1 \times 10^{7} \mathrm{BM}$ MNC was infused by retro-orbital vein injection. Recipients were analyzed beginning at 6 weeks after transplantation.

\section{Plasma von Willebrand factor analysis}

VWF antigen (VWF:Ag) was measured by enzyme-linked immunosorbent assay (ELISA) using a rabbit anti-human VWF polyclonal antibody (IgG) cross-reacting with mouse VWF (produced at the Scripps Research Institute) ${ }^{16}$ Normal pooled plasma from C57BL/6J wild-type (WT) mice was used as a reference and defined as $1 \mathrm{U} / \mathrm{mL}$. VWF multimers were analyzed by electrophoresis through $1 \%$ HGT(P) agarose containing $0.1 \%$ sodium dodecyl sulfate followed by western blotting with the same antibodies used for ELISA. ${ }^{13}$

\section{Flow cytometry analysis}

Mouse blood samples were collected from the retro-orbital plexus using sodium citrate as anti-coagulant. Blood samples were diluted in phosphate-buffered saline $(\mathrm{pH}$ 7.4) containing $2 \mathrm{mM}$ ethylenediaminetetraacetic acid. Samples were stained with anti-CD41 (integrin allb) (MWReg30, Biolegend, San Diego, CA), anti-GPIba (LJ-P3 for hGPIba, 5A7 for mGPIba ${ }^{17}$, MERU-Vaslmmune, San Diego, CA), anti-VWF [polyclonal antibodies ${ }^{13}$ ]). Samples were analyzed using a NovoCyte flow cytometer (ACEA Biosciences). The results were analyzed with FlowJo v.10.7.1.

\section{Results}

\section{Generation and characterization of type 2B von Willebrand disease model mice with humanized von Willebrand factor A1-GPIb $\alpha$ interaction}

We have previously generated a mouse strain expressing human VWF A1/A2 in the context of mouse VWF and human GPIba (VWF ${ }^{\text {hA1 }}$ hGPIb $\left.\alpha\right){ }^{13}$ In the current study, the same strategy was employed to generate a strain having type 2B VWD mutation (p.V1316M) in human VWF exon 28 (encoding A1/A2 domains). The substitution p.V1316M 
was chosen as the mutation associated with the most severe bleeding and thrombocytopenia with morphological abnormalities in patients with type 2B VWD. ${ }^{5}$ A knockin strain having p.V1316M mutation in human VWF exon 28 was cross-bred with transgenic mice expressing human GPIba on platelets.13,18 The mutant VWF allele (p.V1316M) was maintained either in heterozygous (VWF ${ }^{2 B h e t}$ hGPIb $\alpha$ ) or homozy-gous (VWF 2 -Bhomo hGPIb $\alpha$ ) status, and a list of the mouse strains used in the cur- rent study is shown in Figure $1 \mathrm{~A}$. One of our interests in generating type 2B VWD model mice was whether they present macrothrombocytopenia in autosomal dominant manner as observed with human patients. As expected, platelet counts were significantly decreased in both $V_{W}{ }^{2 B h e t} h G P I b \alpha$ and VWF ${ }^{2 B h o m o}$ hGPIb $\alpha$ mice compared to $V_{W}{ }^{\text {hA1 }}$ hGPIb $\alpha$ mice (Figure 1B). Mice having homozygous p.V1316M mutation with mouse GPIba (VWF'2Bhomo mGPIb $\alpha$ ) showed normal platelet count, confirming that

A
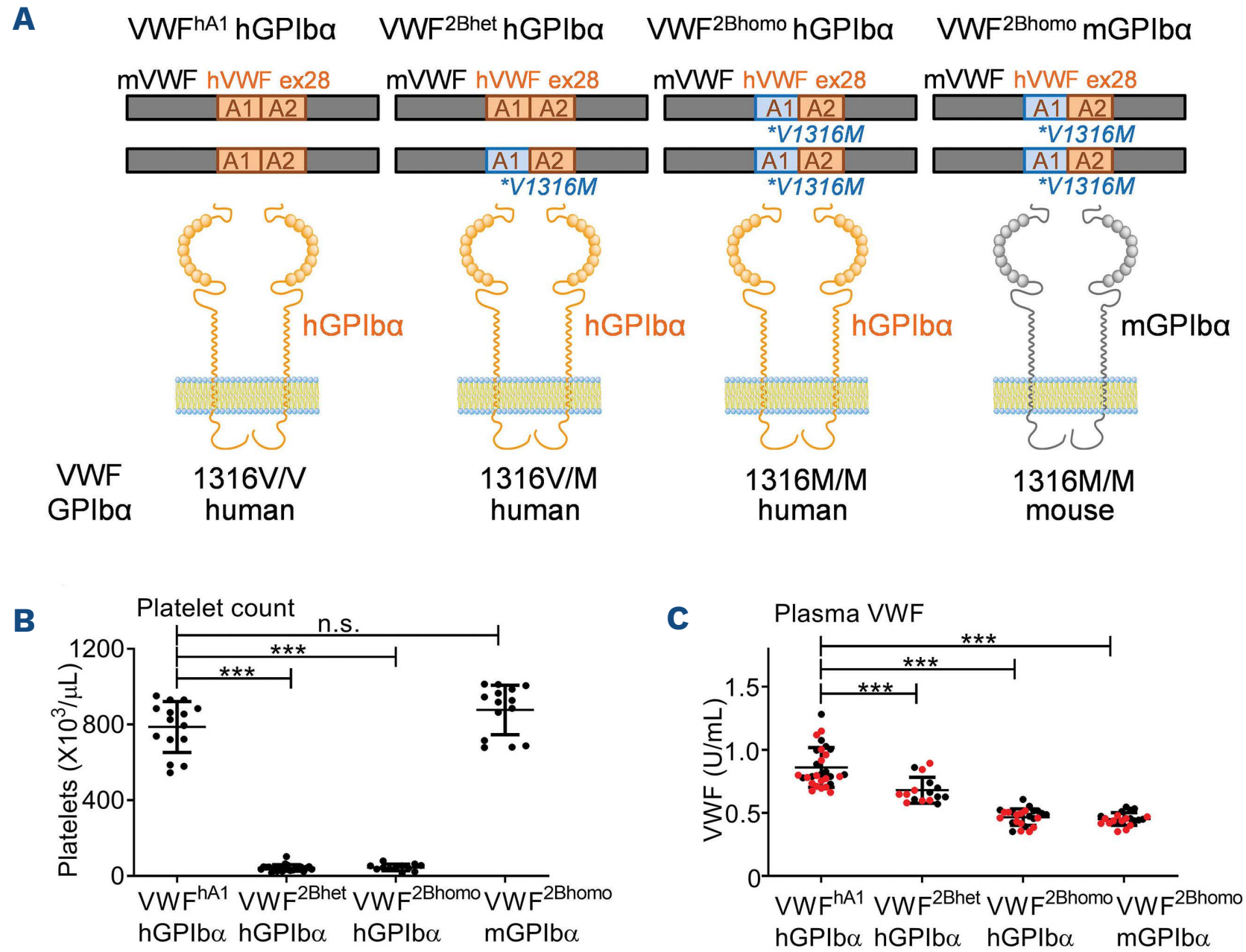

D
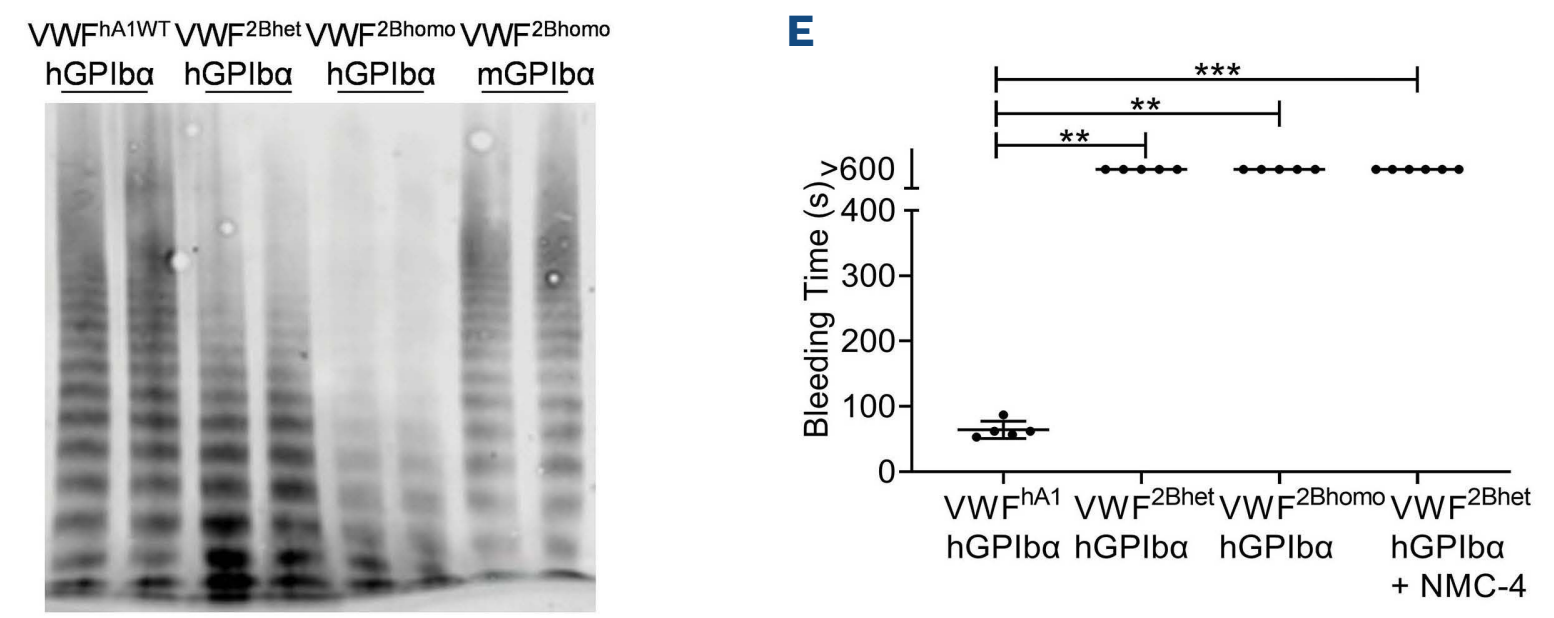

Figure 1. Generation of a mouse model of type 2B von Willebrand disease with humanized von Willebrand factor A1-GPIb $\alpha$ interaction. (A) A knockin strain having human von Willebrand factor (VWF) exon 28 (encoding A1 and A2) bred with human GPIba transgenic strain (VWF ${ }^{\text {hA1 }}$ hGPIb $\alpha$ ) has been previously described.13 A new knockin strain of human VWF exon28 with p.V1316M mutation has been generated in the background of mouse GPIb $\alpha$ (VWF ${ }^{2 B h o m o}$ mGPIb $\alpha$ ) and crossed with human GPIb $\alpha$ transgenic strain, and maintained either heterozygote or homozygote (VWF ${ }^{2 B h e t}$ hGPIbo or VWF ${ }^{2 B h o m o}$ hGPIba, respectively). These 4 mouse strains were analyzed for platelet count (B), plasma VWF (C), and VWF multimer distribution (D). In (C), males and females are depicted as black and red dots, respectively. (E) VWF ${ }^{\text {hA }}$ hGPIb $\alpha$, VWF ${ }^{2 B h e t}$ hGPIb $\alpha$, and VWF ${ }^{2 B h o m o}$ hGPIb $\alpha$ mice ( $n=5$ in each strain)

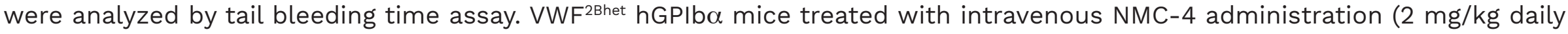
for 4 consecutive days, $n=6$ ) were also tested by tail bleeding time assay on the fourth day. Statistical analysis was performed by Kruskal-Wallis non-parametric test followed by Dunn's multiple comparison test. $\star \star P<0.01, * \star \star P<0.001$. 
thrombocytopenia is caused by gain-of-function VWF mutation only when species compatible GPIb $\alpha$ is expressed. Platelet size was increased in both $\mathrm{VWF}^{2 \mathrm{Bhet}}$ hGPIb $\alpha$ and VWF 2 2Bhomo hGPIb $\alpha$ mice (Online Supplementary Figure S1A). Decrease in the levels of VWF in plasma might be attributed to spontaneous binding to platelet GPIb $\alpha$ and enhanced clearance of high molecular weight (HMW) VWF multimers. In support of this idea, VWF multimer analysis showed loss of HMW VWF multimers in the plasma of VWF ${ }^{2 B h e t}$ hGPIb $\alpha$ and VWF ${ }^{2 B h o m o}$ hGPIb $\alpha$ mice, the effect was more profound in the latter (Figure 1D). In addition, increased susceptibility of type $2 \mathrm{~B}$ mutant VWF to ADAMTS13 has been previously reported ${ }^{4,10}$ and this mechanism may also contribute to loss of HMW VWF multimers in our mice. Interestingly, plasma VWF level was also decreased in VWF ${ }^{2 B h o m o} \mathrm{mGPIb} \alpha$ mice. In this strain, gain-of-function VWF has minimum spontaneous binding to $\mathrm{mGPIb} \alpha$ expressed on platelet surface, and therefore, loss of HMW VWF multimer was less obvious compared to the strains with hGPIba. Decreased plasma VWF in this strain may be, at leaset partly, caused by impaired VWF synthesis, secretion or accelerated degradation. Consistently, plasma VWF level of $V_{W F}^{2 B h o m o}$ hGPIba mice was lower than that of $V_{W}^{2 B h e t}$ hGPIba mice despite similar severity of thrombocytopenia, indicating the presence of additional mechanism for reduced VWF beyond spontaneous binding and clear- ance. As expected, both VWF $^{2 B h e t}$ hGPIb $\alpha$ and VWF $^{2 B h o m o}$ hGPIba mice showed prolonged tail bleeding time which did not stop in 600 seconds $(n=5$ in each strain, Figure 1E).

\section{Activation of circulating platelets in VWF'2Bhet hGPIb $\alpha$ and VWF ${ }^{2 B h o m o}$ hGPIb $\alpha$ mice}

In order to characterize circulating platelets of $\mathrm{VWF}^{2 \mathrm{Bhet}}$ hGPIb $\alpha$ and VWF ${ }^{2 B h o m o}$ hGPIb $\alpha$ mice, blood samples were analyzed by flow cytometry. In both strains, the expression of hGPIba on platelet surface was markedly reduced, and VWF ${ }^{2 B h o m o}$ hGPIb $\alpha$ mouse was more severely affected than VWF ${ }^{2 B h e t}$ hGPIb $\alpha$ mice (Figure 2A). A small proportion of platelets with preserved hGPIb $\alpha$ expression were found in circulation of VWF ${ }^{2 B h e t}$ hGPIb $\alpha$ and VWF ${ }^{2 B h o m o}$ hGPIb $\alpha$ mice with bound VWF on their surface (Figure 2A, upper right quadrant). There was not obvious GPIba cleavage or VWF binding observed with platelets from mice having homozygous p.V1316M mutation with mouse GPIba (VWF ${ }^{2 B h o m o} \mathrm{mGPIb} \alpha$ ), confirming that GPIb $\alpha$ cleavage is triggered by spontaneous binding of gain-of-function mutant VWF (Figure 2B). Western blotting of plasma samples confirmed cleavage of hGPIba, glycocalicin, was abundantly present in VWF ${ }^{2 B h o m o}$ hGPIba mice and $\mathrm{VWF}^{2 \mathrm{Bhet}}$ hGPIb $\alpha$ mice (Figure 2C). GPVI is a collagen receptor expressed on platelets and is also known to be proteolytically cleaved in response to activation stimuli such as

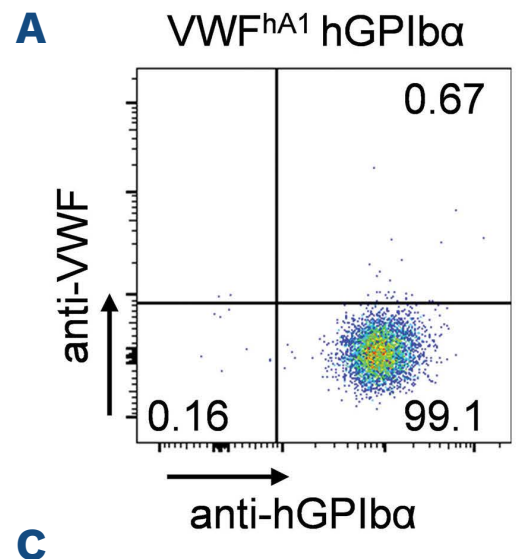

VWF'2Bhet hGPIba
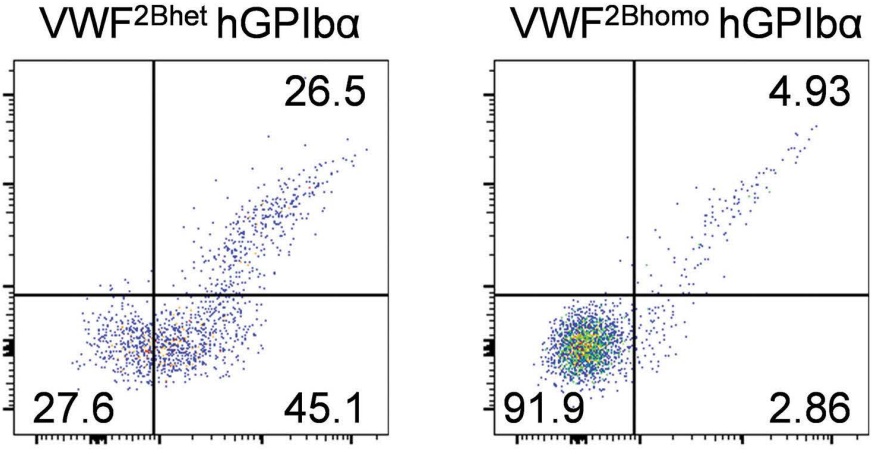

D
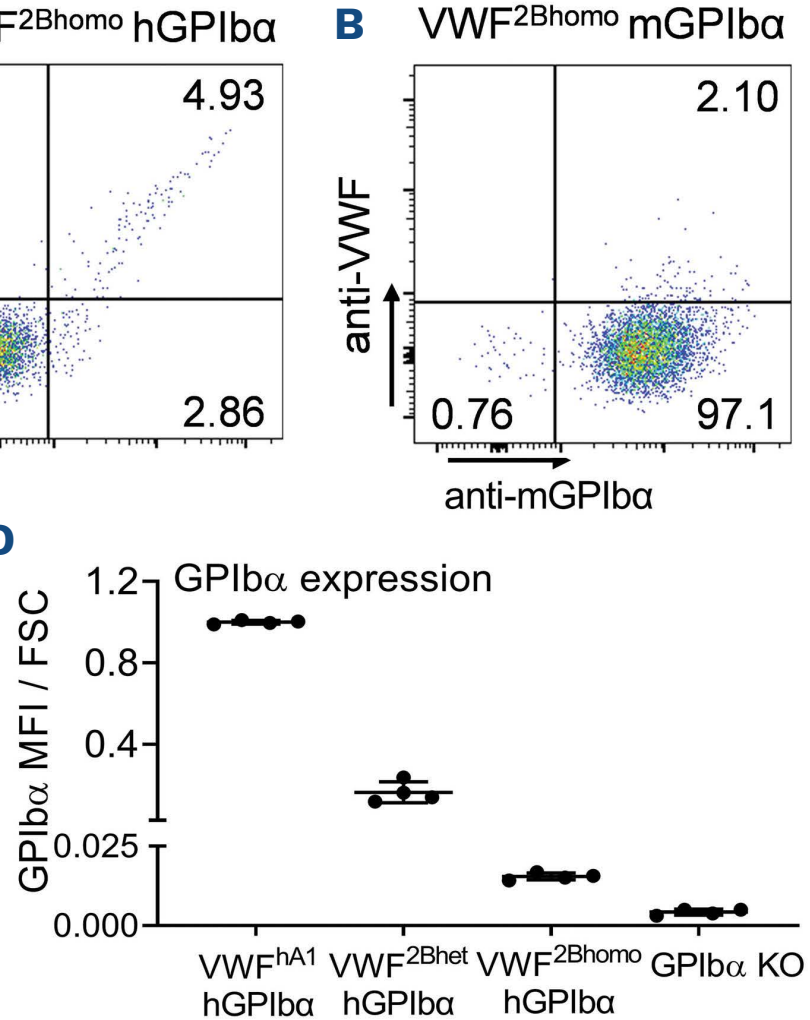

Figure 2. Platelet hGPIb $\alpha$ is cleaved off from platelets in type $2 B$ von Willebrand disease model mice. (A and $B$ ) Whole blood samples collected from each strain were stained with AlexaFluor 488 labeled anti-hGPIbo antibody (LJ-P3) or anti-mGPIb $\alpha$ antibody (5A7) and AlexaFluor 647 labeled von Willebrand factor polyclonal antibody (anti-VWF). After staining, blood cells were analyzed by flow cytometry. (C) Plasma samples collected from 2 mice of each strain were analyzed by sodium dodecyl sulfate gel electrophoresis followed by western blotting. PVDF membrane was probed with anti-glycocalicin polyclonal antibody, and the signal was detected with IRDye 800 goat anti-rabbit IgG. The image was obtained using LI-COR Odyssey imaging system. (D) Mean fluorescence intensity (MFI) of hGPIba signal analyzed by flow cytometry ( $n=4$ in each strain) was normalized by forward side scatter (FSC) MFI to cor-rect platelet size varied among strains. 
ligand engagement, elevated shear, and coagulation. ${ }^{19}$ The expression of GPVI on platelet surface was also decreased in VWF ${ }^{2 B h e t}$ hGPIb $\alpha$ and VWF ${ }^{2 B h o m o}$ hGPIb $\alpha$ mice compared to $V_{W}{ }^{\text {hA1 }}$ hGPIba mice (Online Supplementary Figure S1B). Western blotting of VWF ${ }^{2 B h o m o}$ hGPIb $\alpha$ mouse platelet lysate confirmed loss of full-length hGPIba, leaving C-terminal fragment after shedding (Online Supplementary Figure S1C). Interestingly, the amount of intracellular filamin A ( F n $\mathrm{A}$ ) was decreased in VWF ${ }^{2 B h o m o}$ hGPIb $\alpha$ mouse platelets compared to VWF ${ }^{\mathrm{hA}}$ hGPIb $\alpha$ mouse platelets. The level of FlnA was also quantified by staining platelets intracellularly after fixation and permeabilization, followed by platelet size correction (Online Supplementary Figure S1D). Reduced FlnA content in VWF ${ }^{2 B h o m o}$ hGPIba mouse platelets was confirmed by flow cytometry, indicating activation of $\mu$-calpain and enhanced FlnA degradation in VWF 2 Bhomo hGPIb $\alpha$ mouse platelets. ${ }^{20,21}$ Functional defect of platelets in response to agonist stimulation has been reported in patients and mouse model of type 2B VWD. ${ }^{22-24}$ Thus, mouse platelets have been stimulated with PAR4 activating peptide (PAR4$A P)$ and fibrinogen binding was evaluated by flow cytometry. As expected, fibrinogen binding was impaired in VWF 2 Bhet hGPIba and VWF 2 Bhomo hGPIb $\alpha$ mouse platelets compared to VWF hA1 hGPIba mouse platelets (Online Supplementary Figure S2). Defect in fibrinogen binding following agonist stimulation has also been previously reported in a mouse model of platelet-type VWD. ${ }^{25}$
Contribution of megakaryocyte/platelet versus endothelial cells to the pathophysiology of type 2B von Willebrand disease

Plasma VWF is primarily derived from endothelial cells (EC), and platelets contain $10-15 \%$ of total blood VWF. Thus, one could postulate that the pathology of type $2 B$ VWD is caused by endothelial synthesis of mutant VWF. Previous study showed that VWF spontaneously bound to the surface and intracellular canals of cultured MK derived from patients with type 2B VWD. ${ }^{6}$ This result suggests a possibility that mutant VWF binds to GPIbo during synthesis in $M K$, leading to impaired platelet generation. Thus, reciprocal BM transplantation between VWFA1 hGPIb $\alpha$ and VWF ${ }^{2 B h o m o}$ hGPIb $\alpha$ mice was performed. VWF ${ }^{\text {hA1 }}$ hGPIb $\alpha$ mice lethally irradiated and transplated with VWF 2 Bhomo hGPIb $\alpha$ BM hematopoietic stem cells (HSC) expressed VWF with normal human $A 1$ sequence in $E C$ and gain-of-function mutant VWF (p.V1316M) in MK/platelets (2B ${ }^{M K}$, Figure 3A). Conversely, VWF ${ }^{2 B h o m o}$ hGPIb $\alpha$ mice irradiated and transplanted with VWF ${ }^{\text {hA1 }}$ hGPIb $\alpha$ BM HSC expressed mutant VWF in EC and normal VWF in MK/platelets (2B $\left.{ }^{\mathrm{EC}}\right)$. VWF ${ }^{\text {hA1 }}$ hGPIb $\alpha$ mice irradiated and transplanted with allogenic VWF'A1 hGPIb $\alpha$ mouse BM HSC were prepared as controls. Platelet count analyzed after $B M$ reconstitution showed marked thrombocytopenia in $2 \mathrm{~B}^{\mathrm{EC}}$ (Figure $3 \mathrm{~B}$ ). Platelet count in $2 \mathrm{~B}^{\mathrm{MK}}$ mice was lower than control VWF ${ }^{\text {hA1 }}$ hGPIb $\alpha$ mice but the difference did not reach statistical significance. Flow cytometry
A

\begin{tabular}{|c|c|c|c|c|}
\hline \multirow{2}{*}{$\begin{array}{l}\text { Crossed } \\
\text { BMT mice }\end{array}$} & \multirow{2}{*}{ Recipient } & \multirow{2}{*}{ BM donor } & \multicolumn{2}{|c|}{$\begin{array}{l}\text { VWF expressed } \\
\text { after BM reconstitution }\end{array}$} \\
\hline & & & Endothelial & MK/platelet \\
\hline $\begin{array}{c}2 B^{M K} \\
(n=10)\end{array}$ & $\begin{array}{l}\text { VWFhA1 } \\
\text { hGPIba }\end{array}$ & $\begin{array}{l}\text { VWF'2Bhomo } \\
\text { hGPIba }\end{array}$ & Normal & $2 \mathrm{~B}$ \\
\hline $\begin{array}{c}2 B^{E C} \\
(n=8)\end{array}$ & $\begin{array}{l}\text { VWF'2Bhomo } \\
\text { hGPIba }\end{array}$ & $\begin{array}{l}\text { VWFhA1 } \\
\text { hGPIba }\end{array}$ & $2 B$ & Normal \\
\hline $\begin{array}{l}\text { control } \\
(n=8)\end{array}$ & $\begin{array}{l}\text { WWFhA1 } \\
\text { hGPIba }\end{array}$ & $\begin{array}{l}\text { VWFhA1 } \\
\text { hGPlba }\end{array}$ & Normal & Normal \\
\hline
\end{tabular}

C

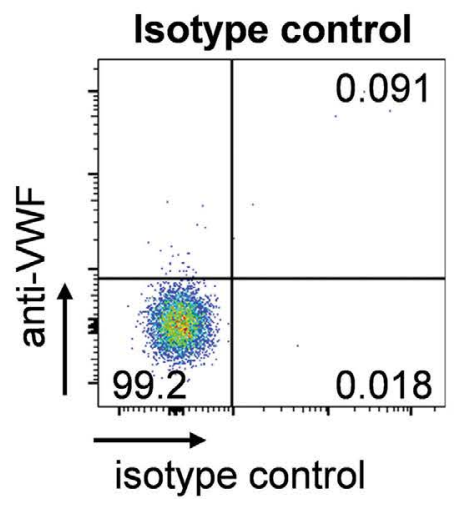

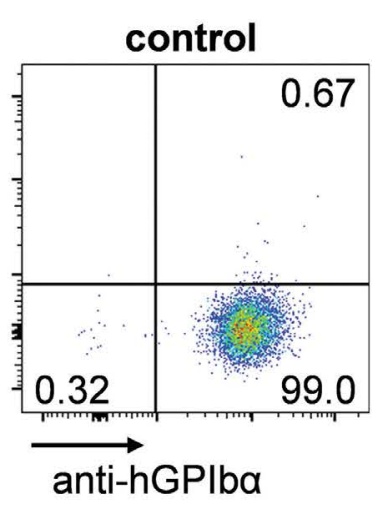

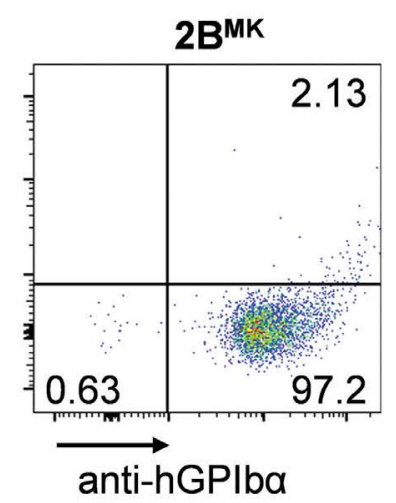

Figure 3. Crossed bone marrow transplantation between VWFA1 hGPIb $\alpha$ and VWF ${ }^{2 B h o m o}$ hGPIb $\alpha$ mice. (A) In order to express type $2 \mathrm{~B}$ von Willebarnd factor (VWF) selectively in endothelial cells (EC) or megakaryocytes[MK]/platelets, VWF ${ }^{\mathrm{hA}}$ hGPIb $\alpha$ and VWF $\mathrm{hWhom}^{2 \mathrm{~B}}$ hGPIb $\alpha$ mice were lethally irradiated (1,100 cGy) and transplanted with hematopoietic stem cells (HSC) derived from the other strain. (B and C) Platelet count and platelet flow cytometry analyses. Surface expression of GPIba and VWF binding were analyzed using the method described in Figure $2 \mathrm{~A}$ after bone marrow (BM) reconstitution. Data are shown as mean \pm standard deviation. Statistical analysis performed with the Kruskal-Wallis non-parametric test followed by Dunn's multiple comparison test. ${ }^{\star} P<0.05$, $\star \star * \star P<0.0001$. 
analysis showed that hGPIb $\alpha$ was shed off from the surface of the $2 \mathrm{~B}^{\mathrm{EC}}$ mouse platelets (Figure $3 \mathrm{C}$ ). The expression of hGPIb $\alpha$ was preserved and platelets with spontaneously bound VWF was not abundantly present in 2B ${ }^{\mathrm{MK}}$ mice (Figure $3 C$, upper right quadrant). These results demonstrate that severe thrombocytopenia and hGPIba cleavage observed with type $2 \mathrm{~B}$ VWD model mice are primarily caused by mutant VWF synthesized in EC.

\section{Enhanced megakaryocyte maturation in the bone} marrow and extramedullary megakaryopoiesis in spleen Previous studies have indicated abnormal megakaryopoiesis and thrombopoiesis in type 2B VWD. The challenging aspect of MK study using patients' samples is the difficulty in obtaining BM cells for analysis because BM aspirate or biopsy is an invasive procedure especially for patients with a bleeding tendency. Therefore, earlier studies have been performed with MK differentiated in vitro from $\mathrm{CD}_{34}{ }^{+}$cells isolated from patients' peripheral blood. ${ }^{6,7}$ In the current study, we have studied newly generated type 2B VWD mouse model to evaluate MK in the $\mathrm{BM}$ and extramedullary megakaryopoiesis in other organs. Interestingly, total number of $\mathrm{MK}$ in the BM was significantly higher in VWF ${ }^{2 B h e t}$ hGPIb $\alpha$ mice compared to VWFA1 hGPIba mice (Figure 4A). MK ploidy analysis showed increased percentage of high ploidy $\mathrm{MK}(32 \mathrm{~N})$ in $\mathrm{VWF}^{2 \mathrm{Bhet}}$ hGPIb $\alpha$ mice compared to VWF ${ }^{\mathrm{h} 1}$ hGPIb $\alpha$ mice (Figure 4B). In order to examine whether increased ploidy observed with VWF ${ }^{2 B h e t}$ hGPIb $\alpha$ mouse BM MK is caused by increased thrombopoietin (TPO) level, plasma TPO was measured by ELISA. Plasma TPO levels in VWF'2Bhet hGPIb $\alpha$ mice were slightly higher than VWF ${ }^{\text {hA1 }}$ hGPIb $\alpha$ mice but the difference was not significant (Figure 4C). Dissection of $\mathrm{VWF}^{2 \mathrm{Bhet}}$ hGPIb $\alpha$ mice showed splemomegaly, indicating the presence of extramedullary hematopoiesis (Figure 4D). As expected, immunofluorescence microscopy showed increased number of MK present in the spleen of $\mathrm{VWF}^{2 B h e t}$ hGPIba mice (Figure 4E and F).
A

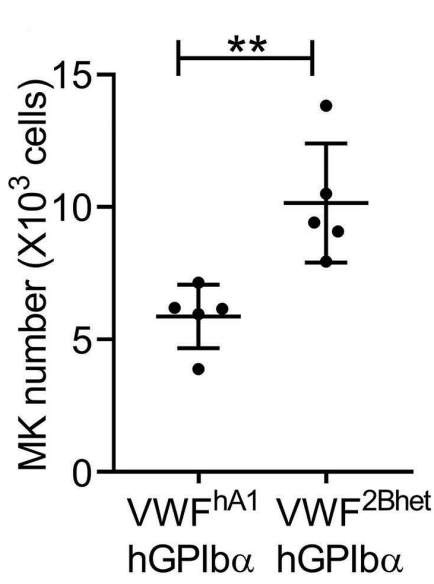

D

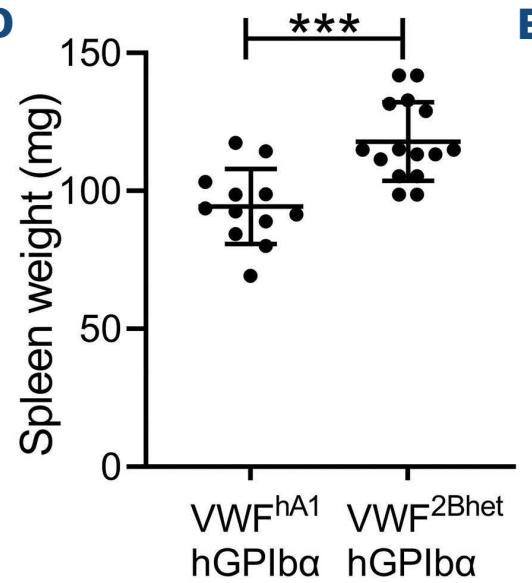

B

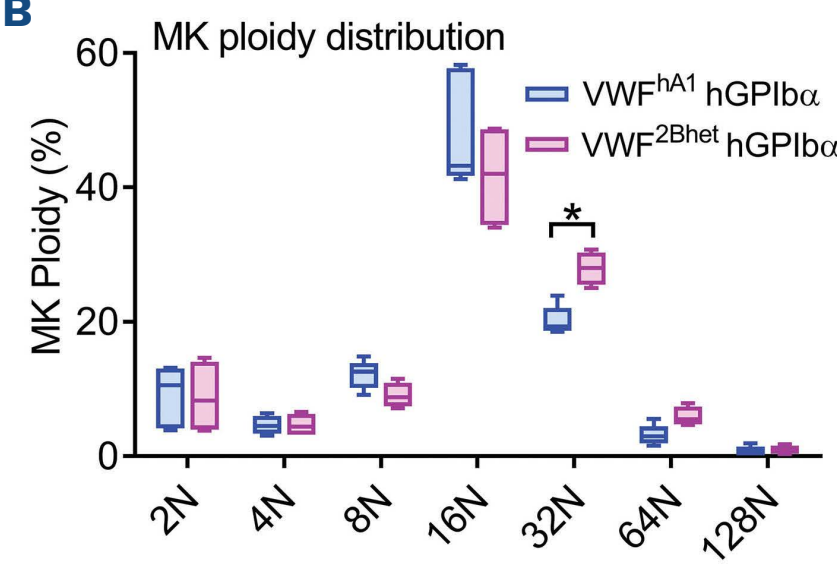

$\mathbf{E}$

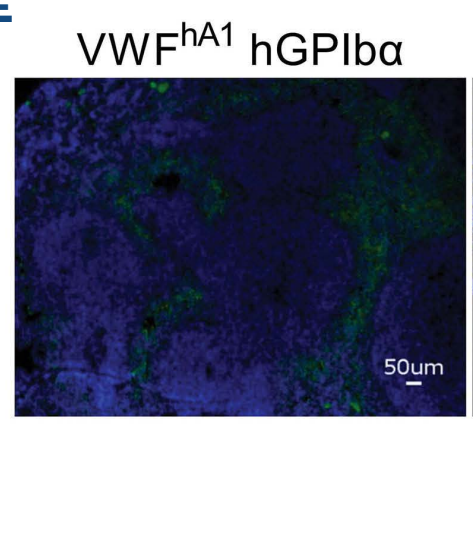

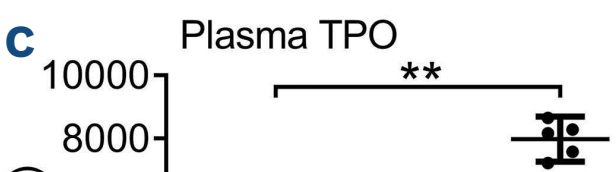

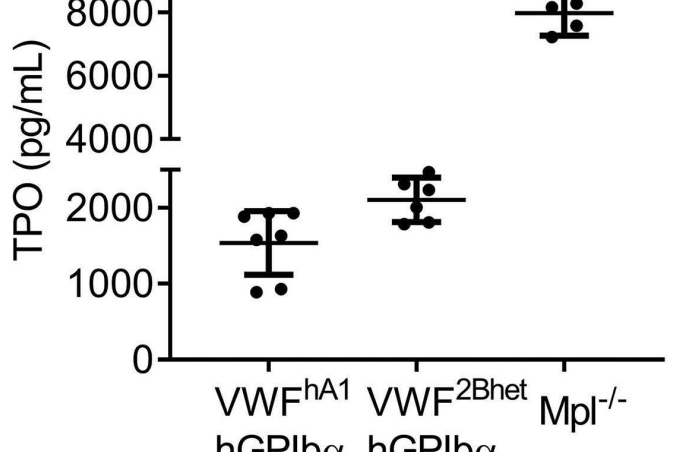

hGPIb $\alpha$ hGPlb $\alpha$

Figure 4. Analysis of megakaryocytes in bone marrow and spleen. (A and B) Bone marrow (BM) cells of VWF'A1 hGPIba and VWF'Bhet hGPIb $\alpha$ mice ( $n=5$ in each group) were flushed from right femurs, stained with Brilliant Violet 421 labeled anti-mouse CD41 antibody and propidium iodide in the presence of RNase A, and analyzed by flow cytometry. Total megakaryocyte (MK) number per femur and MK ploidy distribution are shown. (C) Thyroid peroxidase antibody (TPO) levels in the plasma of VWF ${ }^{\text {hA1 }}$ hGPIba ( $n=7$ ),

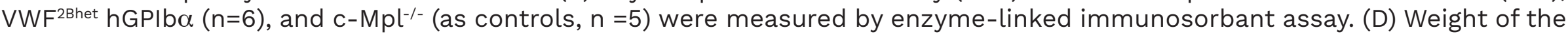
spleens dissected from VWFAl hGPIb $\alpha(n=12)$ and VWF ${ }^{\text {Bhet }}$ hGPIb $\alpha(n=15)$ are shown. Females of 9-11 weeks old mice were used to minimize the effect of body size difference. (E and F) Spleens isolated from VWF ${ }^{\text {ha1 }}$ hGPIb $\alpha$ and VWF ${ }^{2 B h e t}$ hGPIb $\alpha$ mice were cryosectioned and immunostained for MK/platelets using rat anti-mouse CD41 antibody and AlexaFluor488-labeled goat antirat IgG. Nuclei were counterstained with DAPI. Scale bars $=50 \mu \mathrm{m}$. The number of MK per spleen area were counted using BZX700 Fluorescence microscope (Keyence). Data were shown as scatter plots with mean \pm standard deviation or $25^{\text {th }}-75^{\text {th }}$ percentile boxes with min-to-max-whiskers. Data were analyzed by Mann-Whitney non-parametric test in (A) and (F), two-way ANOVA with Šidák's multiple comparisons test in (B), Kruskal-Wallis test with Dunn's multiple comparisons test in (C), and unpaired t-test in (D). ${ }^{*} P<0.05,{ }^{*} P<0.01, * \star * P<0.001$; only significant differences are shown. 
Megakaryocytes bind to and internalize gain-of-function mutant von Willebrand factor of endothelial synthesis

One unsolved question was whether MK have a chance to encounter plasma VWF and are influenced by gain-offunction mutant VWF during thrombopoiesis. In order to distinguish VWF of endothelial and MK origin, BM HSC prepared from $\mathrm{VWF}^{-/-}$hGPIb $\alpha$ mice were transplanted into

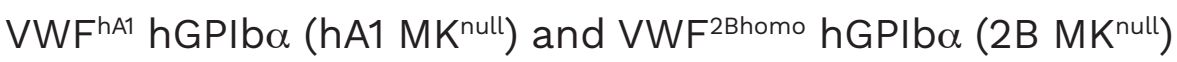
to eliminate VWF synthesis in MK (Figure 5A). hA1 MKnull and 2B $M^{\text {null }}$ mice express VWF with normal human A1 or p.V1316M mutant A1 sequence only in EC. As expected, 2B $M K^{\text {null }}$ presented marked thrombocytopenia and circulating platelets had hGPIba shed-off from surface (Figure 5B). Immunofluorescent analyses confirmed absence of VWF in the $\mathrm{MK}$ of $\mathrm{BM}$ and spleen in the hA1 MKnull mice (Figure $5 \mathrm{C})$. Interestingly, $2 \mathrm{~B} \mathrm{MK}^{\text {null }}$ mice showed weak staining of VWF in the BM MK and strong signal in the splenic MK (Figure 5D). Splenic red pulp harbors an open circulatory system where MK may potentially bind to plasma VWF. ${ }^{26}$ Thus, higher VWF staining observed with splenic MK is in agreement with exposure to an open circulatory system. These results show that in the absence of VWF synthesis in MK, MK of 2B MKull mice contain substantial amount of VWF derived from EC synthesis. In order to further characterize platelets generated from these $\mathrm{MK}$, blood samples were fixed, permeabilized, stained with anti-VWF antibody and analyzed by flow cytometry (Online Supplementary Figure S3). hA1 MKnull platelets had no VWF signal inside because of defective VWF synthesis in MK, and the result was similar to $\mathrm{VWF}^{-/-}$hGPIb $\alpha$ mouse platelets. On the other hand, about half of platelets derived from $2 \mathrm{~B} \mathrm{MK}^{\text {null }}$ mice had VWF inside of cells and partially co-localized with hGPIb $\alpha$ signal. These results confirm that MK of type 2B VWD model mice are exposed to and bind to mutant VWF of EC origin. MK with internalized mutant VWF have potential to produce platelets with intracellular VWF and reduced surface GPIba expression into circulation.

\section{Blocking von Willebrand factor A1-GPIb $\alpha$ interaction inhibits hGPIb $\alpha$ cleavage and ameliorates thrombocytopenia}

In order to test if platelet abnormalities and MK ploidy shift observed with VWF ${ }^{2 B h e t}$ hGPIb $\alpha$ mice can be reversed by inhibiting VWF A1-GPIb $\alpha$ interaction, anti-VWF A1 blocking antibody (NMC-4) was injected in vivo. ${ }^{27,28}$ Daily administration of NMC-4 (2 mg/kg, $\mathrm{n=}$ ) led to platelet count increase to the levels comparable to VWF ${ }^{\text {A1 }}$ hGPIb $\alpha$ mice (Figure 6A). Blocking VWF A1-GPIba interaction also ameli-
A

\begin{tabular}{|c|c|c|c|c|}
\hline \multicolumn{5}{|c|}{ after BM reconstitution } \\
\hline Recipient & BM donor & EC & MK/platelet & Resulting mouse \\
\hline $\begin{array}{l}\text { VWFhA1 } \\
\text { hGPIba }\end{array}$ & $\begin{array}{l}\text { VWF-l- } \\
\text { hGPIba }\end{array}$ & Normal & Null & hA1 MK null \\
\hline $\begin{array}{l}\text { VWF'2Bhomo } \\
\text { hGPIba }\end{array}$ & $\begin{array}{l}\text { VWF-l- } \\
\text { hGPIba }\end{array}$ & 2B & Null & 2B MK $\mathrm{Mull}^{\text {n }}$ \\
\hline
\end{tabular}

C $\mathrm{hA} 1 \mathrm{MK}^{\text {null }}$ mouse

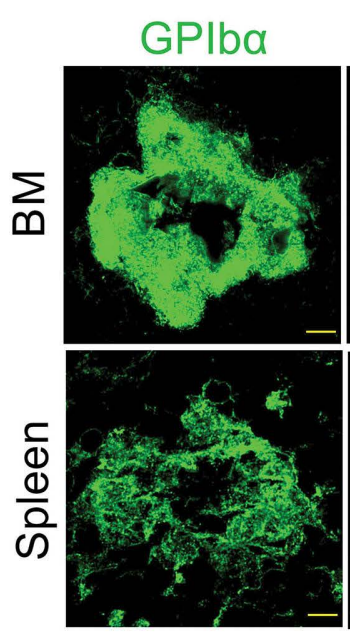

VWF expressed fter BM reconstitution

$2 B$

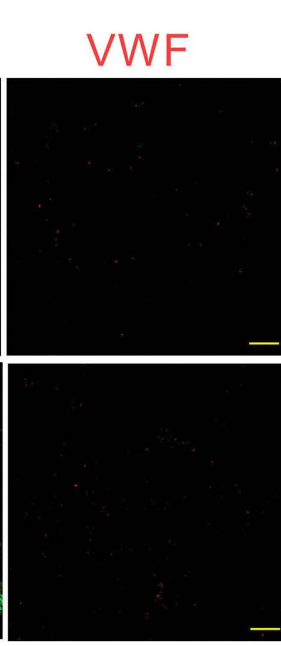

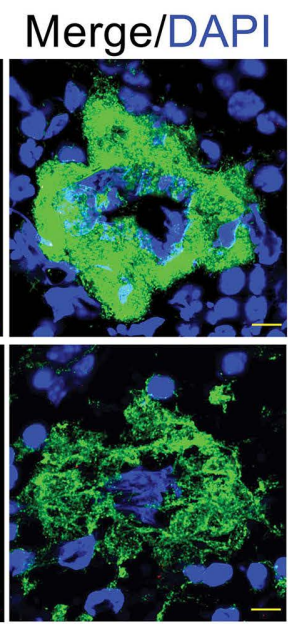

D $2 B M^{\text {null }}$ mouse
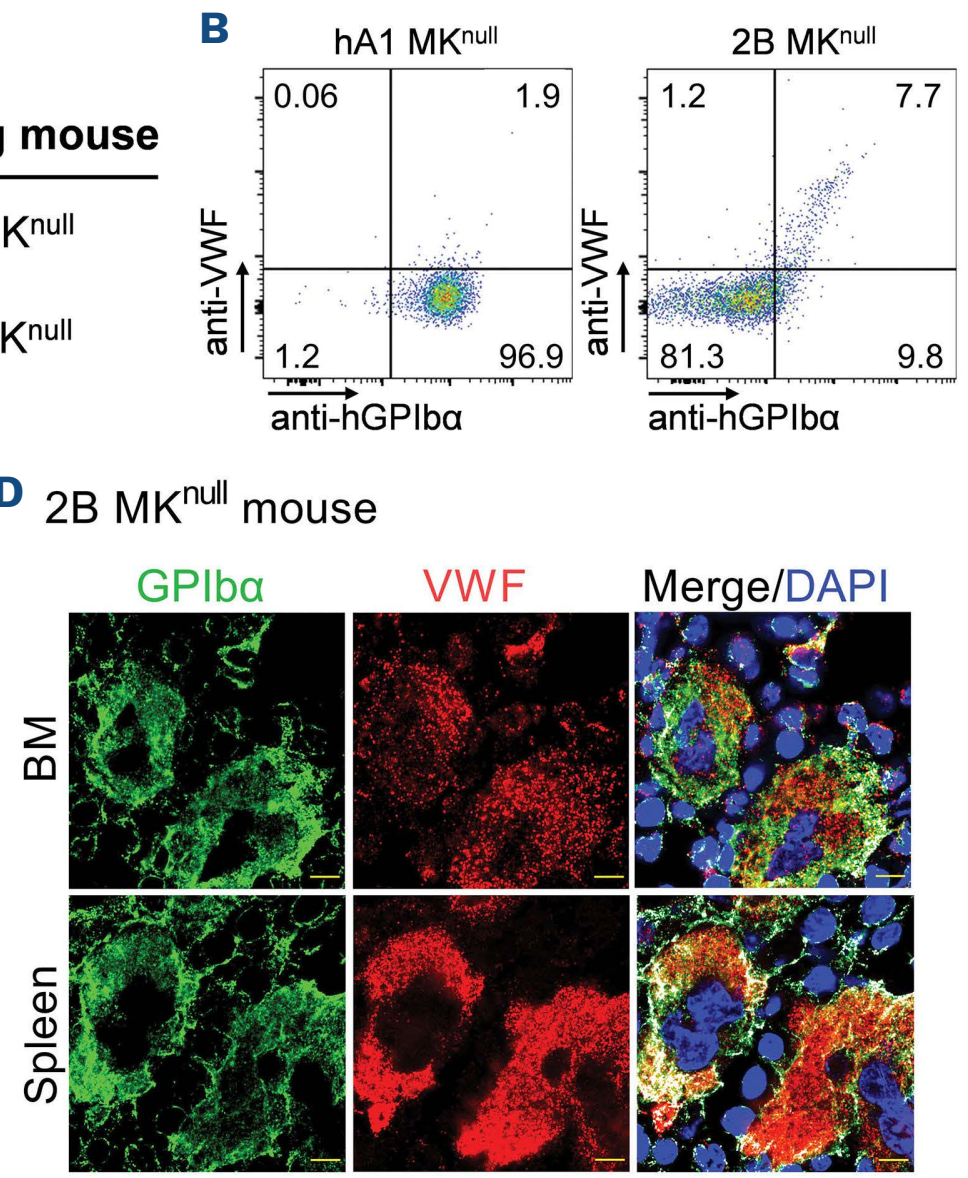

Figure 5. Binding and internalization of gain-of-function mutant von Willebrand factor in megakaryocytes. (A) In order to generate mouse models expressing von Willebrand factor (VWF) only in the endothelial cells (EC), bone marror hematopoietic stem cells

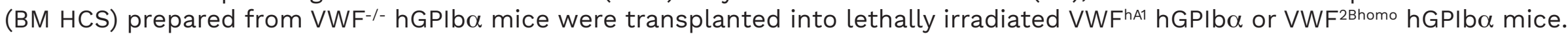
Upon BM reconstitution, resulting mice produce normal or gain-of-function mutant VWF only in the EC. (B) Blood samples were collected from hA1 $\mathrm{MK}^{\text {null }}$ and 2B MKnull mice 6 weeks after transplantation. Representative results of platelet flow cytometry analysis are shown. Blood samples were stained with the method described in Figure 2A. (C and D) Femurs and spleen were snap frozen, cryosectioned, and stained for GPIba (LJ-Ib1, green, MERU-VasImmune), VWF (anti-VWF polyclonal antibody, red), counterstained (DAPI, blue), and analyzed by LSM880 laser scanning confocal microscope (Zeiss). Merged signal of GPIba (green) and VWF (red) is shown in white. Scale bars $=5 \mu \mathrm{m}$. 
orated hGPIba shedding and the hGPIb $\alpha$ expression was recovered on VWF ${ }^{2 B h e t}$ hGPIb $\alpha$ mouse platelets (Figure 6B). It has been known that NMC-4 blocks VWF binding to GPIb $\alpha$, and we have previously reported that administration of NMC-4 $(0.8 \mathrm{mg} / \mathrm{kg})$ prolongs bleeding time even in mice having normal sequence of humanized VWF exon 28 $\left(V W F^{\text {hA1 }}\right.$ hGPIb $\left.\alpha\right) .{ }^{13}$ Thus, as predicted, despite correction of thrombocytopenia and hGPIba expression, tail bleeding time was still prolonged in VWF ${ }^{2 B h e t}$ hGPIb $\alpha$ administered with NMC-4 (see Figure 1E). Interestingly, BM MK analysis performed after 4 doses of NMC-4 injection showed that MK ploidy shift observed with $V_{W F}^{2 B h e t}$ hGPIb $\alpha$ mice was reversed by anti-VWF A1 blocking antibody (Figure 6C, compare with Figure 4B).

\section{Discussion}

Mouse models of type 2B VWD have been described using hydrodynamic injection of mutated mouse VWF expression plasmids into $\mathrm{VWF}^{-/-}$mice. ${ }^{10,11}$ In these models, mutations were introduced into mouse VWF cDNA, and expressed ectopically in the liver, not in EC or MK. Subsequently, a knockin mouse harboring a type 2B VWD mutation (p.V1316M) in mouse $V w f$ gene has been described.12,23 This model enabled physiologic expression in EC and MK and provided valuable information. However, introduction of a single point mutation in the context of mouse VWF did not reproduce platelet phenotype in autosomal dominant manner and had to be bred into homozygous, suggesting that mutagenesis in mouse VWF A1 in association with mouse GPIba may not be identical to that of human. Here, we generated a type 2B VWD model with humanized VWF A1-GPIba interaction. Using the knockin strategy to replace $V w f$ exon 28 - encoding domains $A 1$ and $A 2$ - with that of the human homologue, we have generated a strain with a mutation (p.V1316M) in the sequence of human VWF A1. Subsequent cross-breeding with hGPIba transgenic mice successfully established a mouse model of type 2B VWD that present macrothrombocytopenia in autosomal dominant manner. Reciprocal HSC transplantation determined VWF of endothelial synthesis as the cause of platelet abnormalities. An open question is whether ADAMTS13 sensitivity is altered by $V w f$ exon28 replacement encoding A1 and A2 (ADAMTS13 cleavage) domains. Enhanced susceptibility of type $2 \mathrm{~B}$ VWF by ADAMTS13 has been previously reported and the roles of ADAMTS13-mediated proteolysis in the loss of HMW VWF multimers, regulation of platelet aggregates, and impaired hemostasis have been well established., 4,10 Further study is warranted to explore the alteration of ADAMTS13 sensitivity by humanizing VWF A1/A2 domains in VWF ${ }^{\text {hA1 }}$ hGPIba mice and potential contribution to the phenotype of type 2B VWD model mice.
A

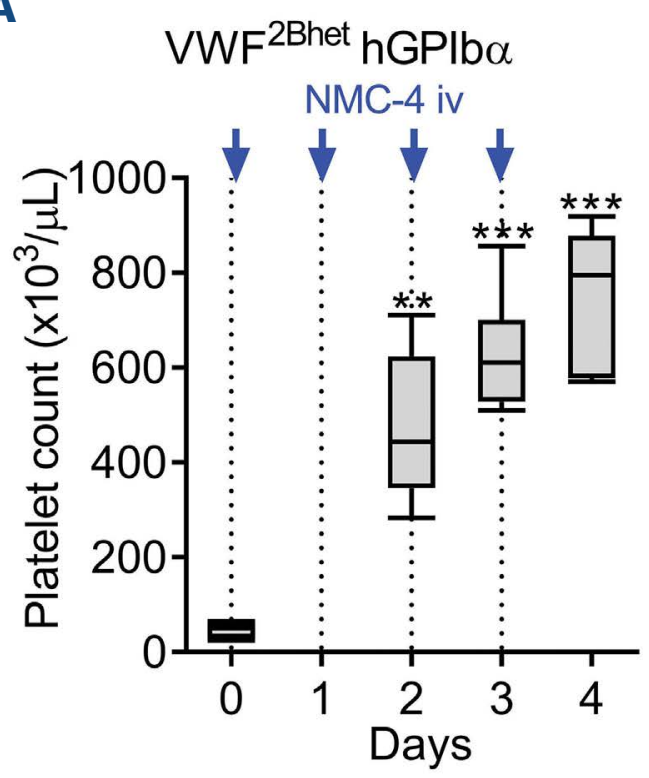

B Control

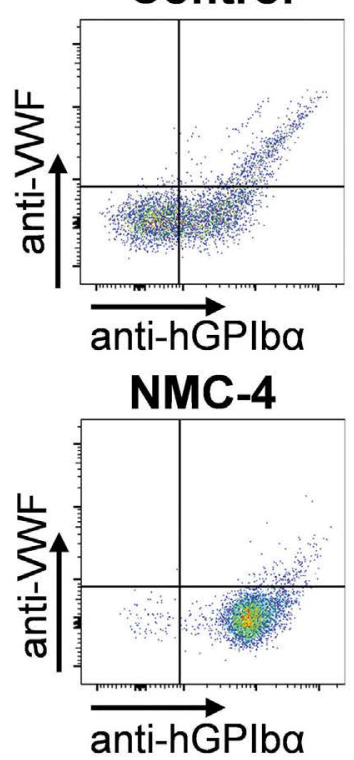

C

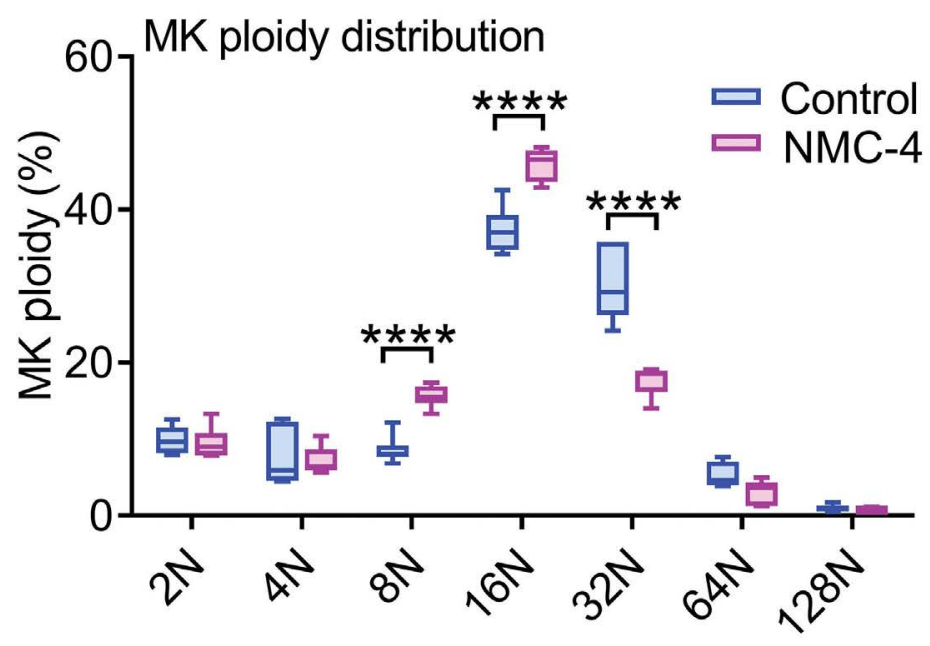

Figure 6. Inhibition of VWF A1-GPIb $\alpha$ reverses the effect of gain-of-function mutant von Willebrand factor on platelets and megakaryocytes. (A) A recombinant monoclonal antibody against von Willebrand factor (VWF) A1 which blocks binding to GPIb $\alpha$ (NMC-4) was intravenously administered into $\mathrm{VWF}^{2 \mathrm{Bhet}}$ hGPIb $\alpha$ mice $(2 \mathrm{mg} / \mathrm{kg}, \mathrm{n}=6)$ daily, and platelet counts were monitored. Data were analyzed by RM one-way ANOVA without assuming sphericity and with Holm-Sidak's post-test for comparing pretreatment values with those at each day post injection. (B) Representative profiles of blood flow cytometry analysis showing recovery of hGPIba expression on VWF $\mathrm{VWhet}^{\text {Bhet }}$ hGPIbo mouse platelets after 4 doses of NMC- 4 administration. (C) Bone marrow (BM) cells of VWF ${ }^{2 B h e t}$ hGPIba mice treated with daily NMC-4 administration were harvested on day 4 and analyzed by flow cytometry as in the Figure 4B. Data are shown as $25^{\text {th }}-75^{\text {th }}$ percentile boxes with min-to-max-whisker and analyzed by two-way ANOVA with Šidák's multiple comparisons test. ${ }^{*} * P<0.01, * * * P<0.001, * * * * P<0.0001$; only significant differences are shown. 
Our type 2B VWD mouse model exhibited exaggerated platelet phenotype compared to human patients. In fact, platelet count in VWF ${ }^{2 B h e t}$ hGPIba mice was about $5 \%$ of the control mice with normal VWF A1 sequence (VWF ${ }^{\text {hA1 }}$ hGPIb $\alpha$ ), which was more severe than human patients having the same mutation. ${ }^{5}$ In addition, hGPIb $\alpha$ was cleaved from platelet surface, and VWF ${ }^{2 B h o m o}$ hGPIba mice were more severely affected than VWF ${ }^{2 B h e t}$ hGPIb $\alpha$ mice. Shedding of mouse GPIb $\alpha$ has also been reported in a study expressing mutant VWF by hydrodynamic gene transfer. ${ }^{24}$ In their study, mouse GPIbo cleavage was not reduced when mutant VWF was expressed in mice deficient in ADAM17, indicating ADAM17-independent cleavage. ${ }^{24}$ Mechanical cleavage by shear stress caused by engagement of hGPIb $\alpha$ binding to VWF A1 may contribute to the shedding of hGPIb $\alpha$. Shedding of hGPIb $\alpha$ from the platelet surface has not been previously documented in human type 2B VWD patients. ${ }^{22}$ Thus, cleavage of hGPIba observed in type $2 \mathrm{~B}$ VWD model might be caused by mouse-specific factors. Of note, both VWF 2 hhet hGPIb $\alpha$ and VWF 2 Bhomo hGPIb $\alpha$ mice presented marked splenomegaly (see Figure 4). In the developing embryo, hematopoiesis occurs in the liver and spleen. In mouse but not in hu-man, the spleen remains as hematopoietic organ throughout the life. ${ }^{29}$ In our study, histological analysis revealed abundant presence of MK in the spleen of VWF ${ }^{2 B h e t}$ hGPIb $\alpha$ and VWF ${ }^{2 B h o m o}$ hGPIb $\alpha$ mice, suggesting extramedullary megakaryopoiesis and potential exposure of MK and platelets to plasma VWF in the open circulatory system of spleen. In support of this idea, transplantation of $\mathrm{VWF}^{-/-}$hGPIba mouse BM into $\mathrm{VWF}^{2 \mathrm{Bhomo}}$ hGPIb $\alpha$ (2B MK ${ }^{\text {null }}$ ) showed splenic MK bound to and internalized plasma-derived mutant VWF, and presence of VWFcontaining platelets in the circulation of $2 \mathrm{~B} \mathrm{MK}^{\text {null }}$ mice. Thus, we speculate that the extramedullary megakaryopoiesis in the spleen contributes to exaggerated platelet phenotype observed with our type 2B VWD model mice.

Another interesting finding is that the expression of gainof-function mutant VWF protein leads to MK ploidy shift to mature population (see Figure 4). Plasma TPO level was not significantly changed in VWF ${ }^{2 B h e t}$ hGPIba compared to $V_{W F}{ }^{\text {ha }}$ hGPIbo, indicating that the ploidy shift was not caused by elevated TPO levels but by direct influence of aberrant VWF binding to MK. In support of this idea, MK ploidy shift observed in VWF ${ }^{2 B h e t}$ hGPIba mouse was reversed by administration of NMC-4 which blocks VWF A1GPIba interaction. Taken together, these results demonstrate that aberrant VWF-hGPIb $\alpha$ occurs not only in platelets but also in MK, the latter leads to altered megakaryopoiesis and possibly platelet generation. We have previously reported signaling effects of GPIb $\alpha$ cytoplasmic tail on MK proliferation and maturation. ${ }^{30}$ Crosstalk of GPIba signaling with TPO-Mpl pathway, mediated by $14-3-3 \xi$ and phosphoinositol-3-kinase/Akt (PI3K/Akt) pathways, might be involved in the effect of gain-of-function mutant VWF on MK proliferation and maturation. ${ }^{30}$ Further study is required to elucidate the mechanism of gain-of-function VWF A1 on GPIba signaling.

As to the functional defect of platelets, impaired activation of the small GTPase Rap1 has been previously reported as a cause of thrombocytopathy and bleeding tendency in type 2B VWD model mice. ${ }^{22}$ Subsequent study determined preactivation and exhaustion of the PKC pathway as the cause of impaired Rap1 signaling and thrombopathy in type 2B VWD. ${ }^{24}$ In addition, the same group identified the effect of dysregulated RhoA/ROCK/LIMK/cofilin pathway on MK and macrothrombocytopenia. ${ }^{23}$ In the current study, we found enhanced degradation of intracellular FlnA, a major substrate for $\mu$-calpain in VWF ${ }^{2 B h e t}$ hGPIb $\alpha$ and VWF ${ }^{2 B h o m o}$ hGPIba mouse platelets (Online Supplementary Figure S1). ${ }^{21,31} \mathrm{FlnA}$ is a scaffold protein which links cytoskeletal proteins to GPIb-IX in platelets and plays an important role in the regulation of contractile force and production of normal size platelets. ${ }^{32,33}$ We have previously reported in a mouse model of sitosterolemia that activation of $\mu$-calpain and enhanced degradation of FlnA led to cytosolic redistribution of $F \ln A$, thereby contributing to generation of large platelets. ${ }^{21}$ In the current study, there was a significant population of VWF ${ }^{2 B h e t}$ hGPIb $\alpha$ and VWF ${ }^{2 B h o m o}$ hGPIb $\alpha$ mouse platelets refractory to agonist stimulation and failed to bind fibrinogen, which was similar to what was previously observed with sitosterolemia mice. Thus, $\mu$-calpain activation and FlnA degradation may partly explain the mechanism for platelet abnormalities observed in type $2 \mathrm{~B}$ VWD. ${ }^{21}$ Further studies are warranted to elucidate the involvement of FlnA in generation of large platelets in type 2B VWD.

Currently, type 2B VWD is treated mostly with VWF replacement therapy with adjunct therapies used for other types of VWD. ${ }^{34} 1$-Desamino-8-D-arginine vasopressin (DDAVP) needs to be carefully considered because of the concern for the exacerbation of thrombocytopenia. VWF A1-GPIba has been focused as a target for the development of therapeutics against type 2B VWD. ${ }^{35-37}$ Interestingly, MK ploidy shift, thrombocytopenia, and GPIba cleavage were found to be corrected by administration of an antibody against VWF A1 which blocks binding to GPIba (NMC-4). However, in agreement with our previous report on VWF hi hGPIb $\alpha$ mice,$^{13}$ tail bleeding time of our type $2 \mathrm{~B}$ VWD mice was not corrected after normalization of platelet counts by highdose NMC-4 administration. Due to the primary role in hemostasis, targeting VWF A1-GPIb $\alpha$ needs to be carefully studied and our animal models serve as useful tools for in vivo evaluation. Dysregulated VWF-GPIba interaction can be seen not only in type $2 B$ VWD but also in platelet-type VWD (PT-VWD), which is caused by mutations in GP1BA. ${ }^{38}$ PT-VWD mouse models have been previously generated and platelet phenotypes similar to type 2B VWD have been reported. ${ }^{25,39-42}$ Thus, results obtained from this study will 
help understand other forms of hematologic disorders which involve dysregulated VWF-GPIb $\alpha$ interaction, and our mouse model with humanized VWF-GPIb interaction may serve as a useful tool to explore therapeutic strategy.

\section{Disclosures}

ZMR is founder, President, and CEO, AZ is Chief Innovation Officer of MERU-VasImmune, Inc. SK and TK have equity interest in MERU-VasImmune, Inc. The remaining authors declare no competing financial interests.

\section{Contributions}

SK designed and performed experiments, analyzed data, and wrote the manuscript; YM performed histologic analysis and flow cytometry analysis; HW is a director of Transgenic Core Facility, Blood Research Institute/Medical College of Wisconsin and helped to design and generate
p.V1316M knockin mouse; $A Z$ provided key reagents; RRM and ZMR supervised the study and reviewed the manuscript; TK designed, directed the study, analyzed data, and co-wrote the manuscript.

\section{Funding}

This work was supported by National Institutes of Health grants HL-56027 and HL-44612 (RRM), HL-135290 (ZMR), and HL-129011 (TK); by fellowships and additional financial support from MERU Foundation (Italy) to YM, SK, and TK; and by the National Foundation for Cancer Research (SK and $T K$ ).

\section{Data-sharing statement}

Further details of the data generated or analyzed in the current study are available from the corresponding author upon request.

\section{References}

1. Nichols WL, Hultin MB, James AH, et al. von Willebrand disease (VWD): evidence-based diagnosis and management guidelines, the National Heart, Lung, and Blood Institute (NHLBI) Expert Panel report (USA). Haemophilia. 2008;14(2):171-232.

2. Ruggeri ZM, Pareti FI, Mannucci PM, Ciavarella N, Zimmerman TS. Heightened interaction between platelets and factor VIII/von Willebrand factor in a new subtype of von Willebrand's disease. N Engl J Med. 1980;302(19):1047-1051.

3. Ruggeri ZM, Lombardi R, Gatti L, Bader R, Valsecchi C, Zimmerman TS. Type IIB von Willebrand's disease: differential clearance of endogenous versus transfused large multimer von Willebrand factor. Blood. 1982;60(6):1453-1456.

4. Rayes J, Hommais A, Legendre P, et al. Effect of von Willebrand disease type $2 \mathrm{~B}$ and type $2 \mathrm{M}$ mutations on the susceptibility of von Willebrand factor to ADAMTS-13. J Thromb Haemost. 2007;5(2):321-328.

5. Federici AB, Mannucci PM, Castaman G, et al. Clinical and molecular predictors of thrombocytopenia and risk of bleeding in patients with von Willebrand disease type 2B: a cohort study of 67 patients. Blood. 2009;113(3):526-534.

6. Nurden P, Debili N, Vainchenker W, et al. Impaired megakaryocytopoiesis in type $2 \mathrm{~B}$ von Willebrand disease with severe thrombocytopenia. Blood. 2006;108(8):2587-2595.

7. Nurden P, Gobbi G, Nurden A, et al. Abnormal VWF modifies megakaryocytopoiesis: studies of platelets and megakaryocyte cultures from patients with von Willebrand disease type $2 \mathrm{~B}$. Blood. 2010;115(13):2649-2656.

8. Chen J, Tan K, Zhou H, et al. Modifying murine von Willebrand factor A1 domain for in vivo assessment of human platelet therapies. Nat Biotechnol 2008;26(1):114-119.

9. Navarrete AM, Casari C, Legendre P, et al. A murine model to characterize the antithrombotic effect of molecules targeting human von Willebrand factor. Blood. 2012;120(13):2723-2732.

10. Rayes J, Hollestelle MJ, Legendre P, et al. Mutation and ADAMTS13-dependent modulation of disease severity in a mouse model for von Willebrand disease type 2B. Blood. 2010;115(23):4870-4877.

11. Golder M, Pruss CM, Hegadorn C, et al. Mutation-specific hemostatic variability in mice expressing common type $2 \mathrm{~B}$ von
Willebrand disease substitutions. Blood. 2010;115(23):4862-4869.

12. Adam F, Casari C, Prevost N, et al. A genetically-engineered von Willebrand disease type $2 \mathrm{~B}$ mouse model displays defects in hemostasis and inflammation. Sci Rep. 2016;6:26306.

13. Kanaji S, Orje JN, Kanaji T, et al. Humanized GPIb $\alpha$-von Willebrand factor interaction in the mouse. Blood Adv. 2018;2(19):2522-2532.

14. Celikel R, Varughese KI, Madhusudan, Yoshioka A, Ware J, Ruggeri ZM. Crystal structure of the von Willebrand factor A1 domain in complex with the function blocking NMC-4 Fab. Nat Struct Biol. 1998;5(3):189-194.

15. Kanaji S, Kuether EL, Fahs SA, et al. Correction of murine Bernard-Soulier syndrome by lentivirus-mediated gene therapy. Mol Ther. 2012;20(3):625-632.

16. Kanaji S, Fahs SA, Shi Q, Haberichter SL, Montgomery RR. Contribution of platelet versus endothelial VWF to platelet adhesion and hemostasis. J Thromb Haemost. 2012;10(8):1646-1652.

17. Yokota N, Zarpellon A, Chakrabarty S, et al. Contributions of thrombin targets to tissue factor-dependent metastasis in hyperthrombotic mice. J Thromb Haemost. 2014;12(1):71-81.

18. Ware J, Russell S, Ruggeri ZM. Generation and rescue of a murine model of platelet dysfunction: the Bernard-Soulier syndrome. Proc Natl Acad Sci U S A. 2000;97(6):2803-2808.

19. Gardiner EE. Proteolytic processing of platelet receptors. Res Pract Thromb Haemost. 2018;2(2):240-250.

20. Artemenko EO, Yakimenko AO, Pichugin AV, Ataullakhanov FI, Panteleev MA. Calpain-controlled detachment of major glycoproteins from the cytoskeleton regulates adhesive properties of activated phosphatidylserine-positive platelets. Biochem J. 2016;473(4):435-448.

21. Kanaji T, Kanaji S, Montgomery RR, Patel SB, Newman PJ. Platelet hyperreactivity explains the bleeding abnormality and macrothrombocytopenia in a murine model of sitosterolemia. Blood. 2013;122(15):2732-2742.

22. Casari C, Berrou E, Lebret M, et al. von Willebrand factor mutation promotes thrombocytopathy by inhibiting integrin alphallbbeta3. J Clin Invest. 2013;123(12):5071-5081. 
23. Kauskot A, Poirault-Chassac S, Adam F, et al. LIM kinase/cofilin dysregulation promotes macrothrombocytopenia in severe von Willebrand disease-type 2B. JCI Insight. 2016;1(16):e88643.

24. Casari C, Paul DS, Susen $S$, et al. Protein kinase $C$ signaling dysfunction in von Willebrand disease (p.V1316M) type 2B platelets. Blood Adv. 2018;2(12):1417-1428.

25. Guerrero JA, Kyei M, Russell S, et al. Visualizing the von Willebrand factor/glycoprotein Ib-IX axis with a platelet-type von Willebrand disease mutation. Blood. 2009;114(27):5541-5546.

26. Steiniger $B$, Bette $M$, Schwarzbach $H$. The open microcirculation in human spleens: a three-dimensional approach. J Histochem Cytochem. 2011;59(6):639-648.

27. Fujimura Y, Usami Y, Titani K, et al. Studies on anti-von Willebrand factor (VWF) monoclonal antibody NMC-4, which inhibits both ristocetin- and botrocetin-induced VWF binding to platelet glycoprotein Ib. Blood. 1991;77(1):113-120.

28. Celikel R, Madhusudan, Varughese $\mathrm{KI}$, et al. Crystal structure of NMC-4 fab anti-von Willebrand factor A1 domain. Blood Cells Mol Dis. 1997;23(1):123-134.

29. Wolber FM, Leonard E, Michael S, Orschell-Traycoff CM, Yoder MC, Srour EF. Roles of spleen and liver in development of the murine hematopoietic system. Exp Hematol. 2002;30(9):1010-1019.

30. Kanaji T, Russell S, Cunningham J, Izuhara K, Fox JE, Ware J. Megakaryocyte proliferation and ploidy regulated by the cytoplasmic tail of glycoprotein Ibalpha. Blood. 2004;104(10):3161-3168.

31. Gardiner EE, Karunakaran D, Shen Y, Arthur JF, Andrews RK, Berndt MC. Controlled shedding of platelet glycoprotein (GP)VI and GPIb-IX-V by ADAM family metalloproteinases. J Thromb Haemost. 2007;5(7):1530-1537.

32. Falet $\mathrm{H}$, Pollitt AY, Begonja AJ, et al. A novel interaction between FlnA and Syk regulates platelet ITAM-mediated receptor signaling and function. J Exp Med. 2010;207(9):1967-1979.
33. Kanaji T, Ware J, Okamura T, Newman PJ. GPIbalpha regulates platelet size by controlling the subcellular localization of filamin. Blood. 2012;119(12):2906-2913.

34. Kruse-Jarres R, Johnsen JM. How I treat type 2B von Willebrand disease. Blood. 2018;131(12):1292-1300.

35. Jilma-Stohlawetz P, Knöbl P, Gilbert JC, Jilma B. The anti-von Willebrand factor aptamer ARC1779 increases von Willebrand factor levels and platelet counts in patients with type $2 \mathrm{~B}$ von Willebrand disease. Thromb Haemost. 2012;108(2):284-290.

36. Hulstein JJ, de Groot PG, Silence K, Veyradier A, Fijnheer R, Lenting PJ. A novel nanobody that detects the gain-of-function phenotype of von Willebrand factor in ADAMTS13 deficiency and von Willebrand disease type 2B. Blood. 2005;106(9):3035-3042.

37. Jilma B, Paulinska P, Jilma-Stohlawetz P, Gilbert JC, Hutabarat R, Knöbl P. A randomised pilot trial of the anti-von Willebrand factor aptamer ARC1779 in patients with type $2 \mathrm{~b}$ von Willebrand disease. Thromb Haemost. 2010;104(3):563-570.

38. Scott JP, Montgomery RR. The rapid differentiation of type IIb von Willebrand's disease from platelet-type (pseudo-) von Willebrand's disease by the "neutral" monoclonal antibody binding assay. Am J Clin Pathol. 1991;96(6):723-728.

39. Suva LJ, Hartman E, Dilley JD, et al. Platelet dysfunction and a high bone mass phenotype in a murine model of platelet-type von Willebrand disease. Am J Pathol. 2008;172(2):430-439.

40. Kaur H, Corscadden K, Ware J, Othman M. Thrombocytopathy leading to impaired in vivo haemostasis and thrombosis in platelet type von Willebrand disease. Thromb Haemost. 2017;117(3):543-555.

41. Bury L, Falcinelli E, Mezzasoma AM, Guglielmini G, Momi S, Gresele P. Platelet dysfunction in platelet-type von Willebrand disease due to the constitutive triggering of the Lyn-PECAM1 inhibitory pathway. Haematologica. 2022;107(7):1643-1654.

42. Bury L, Malara A, Momi S, Petito E, Balduini A, Gresele P. Mechanisms of thrombocytopenia in platelet-type von Willebrand disease. Haematologica. 2019;104(7):1473-1481. 